\title{
A NEURO-FuZZY APPROACH FOR THE FAULT LOCATION ESTIMATION OF UNSYNCHRONIZED TwO-TERMINAL TransMisSION LINES
}

\author{
Ramadoni Syahputra \\ Department of Electrical Engineering, Faculty of Engineering, \\ Universitas Muhammadiyah Yogyakarta, Yogyakarta, 55183, INDONESIA \\ ramadoni@umy.ac.id
}

\begin{abstract}
Overhead transmission line is an element of electrical power systems that are most frequently experienced short circuit faults compared to other power system elements. Short circuit faults on overhead transmission line cause a relatively large current and therefore can damage mechanically the electrical equipment connected to the system. The protection system is essentially needed in this situation. In addition, it takes a piece of equipment that can detect the location of fault in order to expedite the repair process, especially if the fault is permanent state. In this paper, a neuro-fuzzy aprroach for short circuit fault location estimation which uses data from both ends of overhead transmission line is described. The approach utilizes the advantages of digital relaying which are available today. The unsynchronized data of fault voltages and currents at two-end of overhead transmission line is applied in this technique. The accurate fault location estimation technique has irrespective of source impedances, fault resistances, fault types, and load currents. Simulation of short circuit fault of transmission line has done by using EDSA software. Short circuit currents and voltages from both ends of overhead transmission line have used to input data of neuro-fuzzy method in Matlab program. Simulation results demonstrate the accuracy of the method. The results shows that the lowest estimation error for single phase to ground fault with the variation of fault resistances of $0 \mathrm{ohms}, 10 \mathrm{ohms}, 50 \mathrm{ohms}$, and $100 \mathrm{ohms}$, respectively, is $0.0027 \%$, while the highest estimation error is $0.2962 \%$.
\end{abstract}

\section{KEYWORDS}

Neuro-Fuzzy, Two-terminal fault location algorithm, transmission line, unsynchronized sampling.

\section{INTRODUCTION}

The transmission line is an element of electrical power systems that are most frequently experienced short circuit faults compared to other electrical power system elements, with the percentage of probability of occurrence of 50\% [1]. There are four types of short circuit faults on a transmission line, i.e., single phase to ground fault, phase to phase fault, double phase to gound fault and symmetrical three-phase fault. Short circuit faults on overhead transmission line cause a relatively large current and therefore can damage mechanically the electrical equipment connected to the system. In addition, it takes a piece of equipment that can detect the location of fault in order to expedite the repair process, especially if the fault is permanent. The continuous and reliable electrical energy supply is the aim of electrical power system operation. The short circuit faults on the line must be estimated accurately to allow maintenance operators to arrive at the scene and repair the faulted transmission line part as soon as possible. Geographical layout and rugged terrain make some sections of electrical power transmission lines difficult to reach;

DOI : $10.5121 /$ ijcsit.2013.5102 
therefore, the robustness of fault location estimation under a variety of power system operating constraints and fault conditions is an important requirement. Therefore, it is important to know where the location of a faulted transmission line section has been occured. Development of the application of digital and microprocessor-based power protection systems has been motivated for fault location technique researchers in the last few decades [2]-[4]. However, accuracy of the distance to the fault determination from a power substation is affected by several stochastic factors. There are some factors which affecting the accuracy of fault estimation, i.e., fault resistance, equivalent impedances of transmission line, effect of the load variation and imprecisions of the transmission line parameters measurements [4]-[6]. Therefore, the accuracy of fault distance determination from both ends of transmission line may be insufficient.

Accurate location of faults on overhead electrical power transmission lines for the inspectionrepair purpose is of vital importance for utility staff and operators for expediting service restoration, and thus to reduce outage time, operating costs and customer complains. During the last decade a number of fault location algorithms have been developed, including the transientstate approach, steady-state phasor approach, the traveling-wave approach, the lumped parameter approach, and the differential equation approach [7], as well as two-end [8] and one-end [9] algorithms. In the last category, synchronized [10] and non-synchronized [11] sampling techniques are used. However, two-terminal data are not widely available on the protection equipment. Fault location determination methods using the measured voltage and current at one terminal channel is still inadequate because it does not take into account the current channel interference from the other terminal. In [12] usage of synchronized measurements of currents and voltages from all two terminals of transmission line has been considered. They have used the distributed parameter models of the overhead transmission line sections. The approach assures high accuracy of fault location estimation, and the faulted transmission line section is also rely on indicated [12]. Then the use of three-terminal unsynchronized measurements of short circuit fault currents and voltages has been considered in [13]. They have used the lumped parameter models of the overhead transmission line sections. It was implied that the error estimation resulting from such simplification is minimized due to the redundancy of the fault location equations. Yet another utilization of three end unsynchronized measurements has been proposed in [14], where exchanging the minimal amount of information between the line terminals over a protection channel was considered. After that, the development of fault location techniques for three terminal transmission lines that utilizing only from two-end synchronized measurements of currents and voltages has been studied in [15]-[16]. From a practical viewpoint, it is desirable for equipment to use only one-terminal data. The one-end algorithms, in turn, utilize different assumptions to replace the remote end measurements. Most of fault location algorithms are only based on local measurements. The use of fuzzy logic based in electrical power system study has been became an interesting research in two last decades [17]. Currently, the most widely used method of overhead transmission line fault location is to determine the apparent reactance of the line during the time that the short circuit fault current is flowing and to convert the ohmic result into a distance based on the parameters of the line. It is widely recognized that this method is subject to errors when the fault resistance of the transmission line is high and the line is fed from both ends (substation), and when parallel circuits exist over only parts of the length of the faulty line.

In this paper, a neuro-fuzzy approach for short circuit fault location estimation, which utilizes unsynchronized measurements of currents and voltages at two-terminal of transmission line is proposed. The measurements has used to input data for training process in neuro-fuzzy system. The lumped parameter in medium transmission line model is strictly used. The approach can be applied in digital distance protection which is available today in electrical power system. The method allows for accurate estimation of short circuit fault location irrespective of fault types, 
fault resistance, load currents, and source impedances. The powerful of both EDSA software and Matlab software have used in this study.

\section{FUNDAMENTAL THEORY}

\subsection{Faults in Transmission Lines}

Transmission lines is one of the main component in electric power systems. Transmission line is a component of electrical power systems that are most frequently experienced faults compared to other power system elements. Faults in power systems are basically classified as shunt faults and series faults [18]. Both types can be balanced fault or unbalanced fault. Faults on a transmission line can occur as whether single or simultaneous faults. Most of faults in transmission lines are single line to ground type. Therefore, the single line to ground fault with various fault resistances is used in this study.

Simultaneous faults on a transmission line consist of a combination of the same or different types of faults. The preferred model for fault calculation is the nodal approach in the frequency domain with transmission line symmetrical components or in the time domain with space phasors or its components. Conventional techniques for fault location calculation are usually based on admittance equations in admittance form. Another general problem is the treatment of simultaneous line faults. Each fault is characterized by the so-called boundary conditions regarding the currents and voltages at the fault location of transmission line.

In an electrical power system comprising of any various interacting elements, there always exists a possibility and probability of faults. The emerge of large power generating stations and highly interconnected power systems via any overhead transmission lines makes early fault detection and rapid equipment isolation imperative to maintain the stability of the system. Faults on overhead transmission lines need to be detected rapidly, located accurately and repaired as soon as possible. Fault detector module of a transmission line protective device can be used to start other relaying modules. The detectors provide an additional way of security in a power protection relaying application as well, and the location of short circuit fault must be determined.

Besides being used to accurately locate a fault, such an method can be used for automated fault analysis. Any occurrence of a short circuit fault should be detected and cleared by the power protective relaying devices. A power protective relaying operation analysis is required if an assessment of its performance is needed. In order to perform the analysis, one has to have a reference method with which to compare the digital relay operation. The fault location technique that can provide both fault type classification and accurate location is an ideal reference for the robust digital protective relaying operation. The technique can be incorporated into a fault analysis automatically by providing high speed information of the fault type and fault location. This is important information for determining if a power protective relay has operated correctly since the relay is also supposed to determine both type and location of fault. The location of fault determined by the distance relay does not have to be too accurate since it only has to determine the zone of the occurrence of fault. The appropriate location of the fault provided by the fault location technique is more accurate and is needed by power operators.

\subsection{Neuro-Fuzzy Method}

During the last two decades adaptive neuro-fuzzy approach has been became a popular method in control area. In this part, a brief description of the adaptive neuro-fuzzy inference system (ANFIS) principles is given which are refered to [19]. The fundamental structure of the type of 
fuzzy inference system (FIS) could be seen as a model that maps input characteristics to input membership functions. After that, it maps all membership function as input to rules and rules to a set of characteristics of FIS output. On the last step, FIS maps characteristics of output to membership functions as output, and the membership function as output to a decision associated with the output. As can be seen that FIS has been stated only non-arbitrary membership functions that were chosen arbitrarily. Fuzzy inference system (FIS) is only used to modeling systems whose the structure of fuzzy rule is essentially predetermined by the operator interpretation of the variable characteristics in the model. However, it cannot be distinguish what the FIS membership functions should look like simply from the data for some situations. Parameters of FIS could be chosen so as to tailor the membership functions to the input and output data rather than choosing the parameters associated with a given membership function arbitrarily in order to account for these types of variations in the values of data. Therefore, the necessity of an adaptive properties in fuzzy inference system becomes obvious.

The adaptive neuro learning concept works similarly to the artificial neural networks. Neuroadaptive learning techniques provide a method for the fuzzy modeling procedure to learn information about a data set. It computes the membership function parameters that best allow the associated fuzzy inference system to track the given input and output data. A network-type structure similar to that of an artificial neural network can be used to interpret the input and output map so it maps inputs through input membership functions and associated parameters, and then through output membership functions and associated parameters to outputs. Through the learning procedure, parameters which associated with the membership functions will changes. The parameters computation is facilitated by a vector of gradient. The vector of gradient determine a criterion of how well the fuzzy inference system (FIS) is modeling the input and output data for a given parameters set. While the vector of gradient is obtained, several optimization procedures can be used in order to control the parameters to reduce some error measure (index of performance). The error measure is comonly defined by the sum of the squared difference between desired and actual outputs. ANFIS uses a combination of back propagation procedure and least squares estimation for membership function parameter estimation. 
International Journal of Computer Science \& Information Technology (IJCSIT) Vol 5, No 1, February 2013

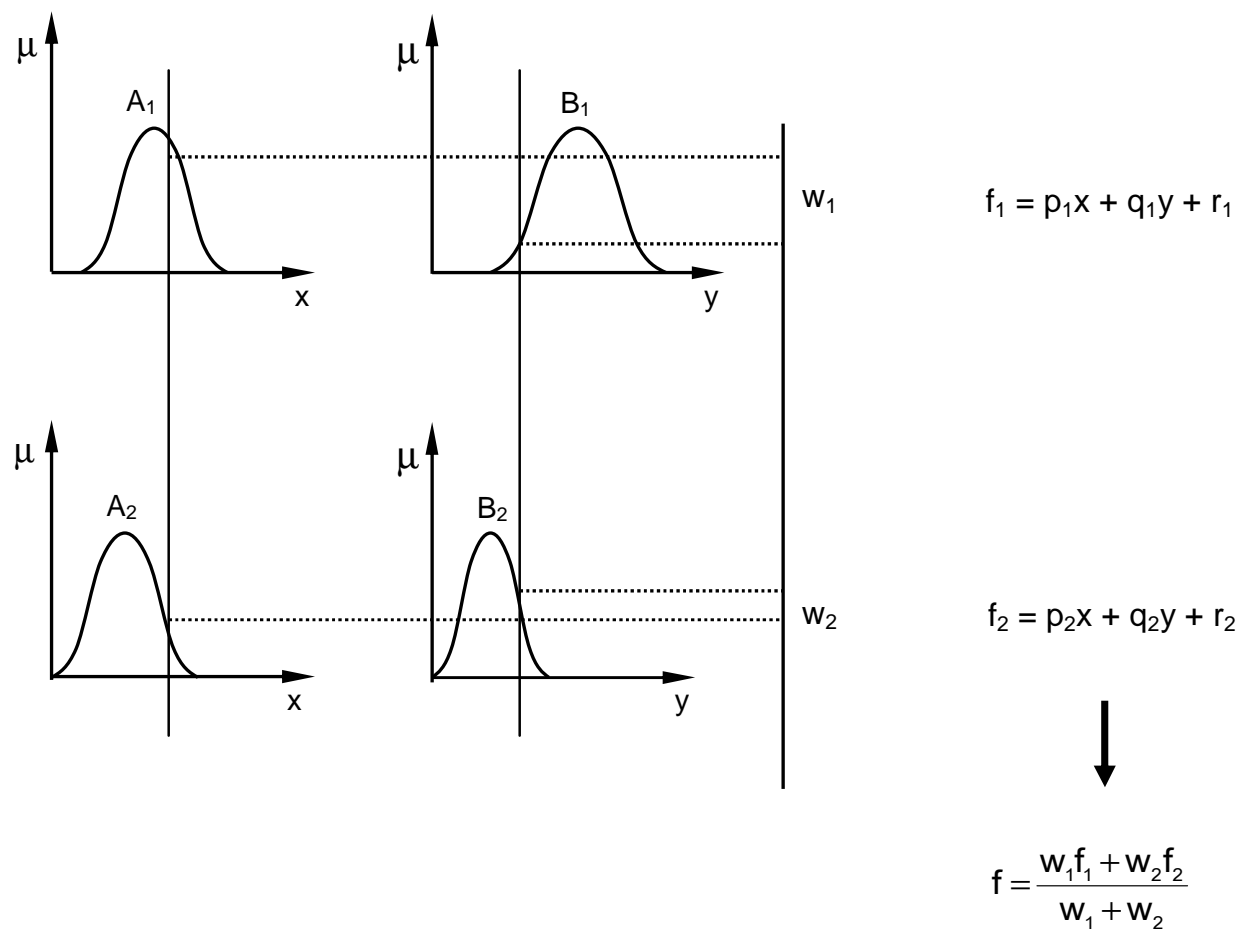

Figure 1. Sugeno's fuzzy logic model

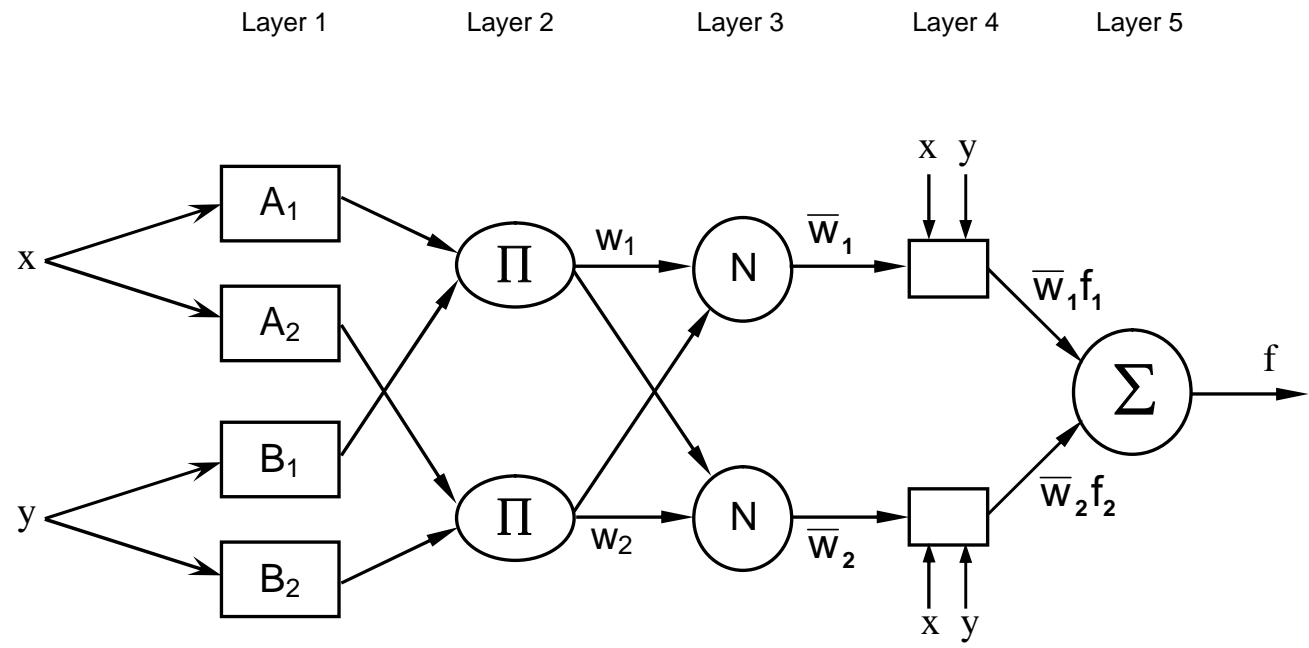

Figure 2. The architecture of the ANFIS.

The suggested ANFIS has several properties:

1. The ANFIS output is Sugeno-type of zero-th order.

2. ANFIS has only a single output which obtained using defuzzification process of weighted average. All output membership functions are constant.

3. It has no rule sharing. The number of rules must be equal to the number of output membership functions.

4. It has unity weight for each rule. 
Figure 1 shows Sugeno's fuzzy logic model. The ANFIS architecture is shown in Figure 2. The architecture comprising by input, fuzzification layers, inference unit and defuzzification layers. The ANFIS architecture can be desripted as consisting of $\mathrm{N}$ neurons in the input layer and $\mathrm{F}$ membership functions for each input, and $\mathrm{F}^{*} \mathrm{~N}$ neurons in the fuzzification layer. The inference unit and defuzzification have FN rules with FN neurons, while the output layer has one neuron. For simplicity, it is assumed that the fuzzy inference system under consideration has two inputs $\mathrm{x}$ and $y$ and one output $z$ as shown in Figure 2. For a zero-order Sugeno fuzzy model, a common rule set with two fuzzy if-then rules is the following:

Rule 1: If $\mathrm{x}$ is $\mathrm{A} 1$ and $\mathrm{y}$ is $\mathrm{B} 1$, Then $\mathrm{f} 1=\mathrm{r} 1$

Rule 2: If $\mathrm{x}$ is $\mathrm{A} 2$ and $\mathrm{y}$ is $\mathrm{B} 2$, Then $\mathrm{f} 2=\mathrm{r} 2$

Here the output of the $\mathrm{i}$-th node in layer $\mathrm{n}$ is denoted as $\mathrm{O}_{\mathrm{n}, \mathrm{i}}$ :

Layer 1. Every node $\mathrm{i}$ in this layer is a square node with a node function:

$$
\begin{aligned}
& \mathrm{O}_{\mathrm{i}}^{1}=\mu \mathrm{A}_{\mathrm{i}}(\mathrm{x}), \text { for } \mathrm{i}=1,2, \\
& \quad \text { or, } \\
& \mathrm{O}_{\mathrm{i}}^{1}=\mu \mathrm{B}_{\mathrm{i}-2}(\mathrm{y}), \text { for } \mathrm{i}=3,4
\end{aligned}
$$

where $x$ is the node-i input, and $A_{i}$ is the label of linguistic terms (big, low, etc.) associated with this node function. $O_{i}^{1}$ is the $A_{i}$ membership function. $O_{i}^{1}$ specifies the degree to which the given $\mathrm{x}$ satisfies the $\mathrm{A}_{\mathrm{i}}$. Usually $\mu \mathrm{Ai}(\mathrm{x})$ is chosen to be bell-shaped with maximum equal to 1 and minimum equal to 0 , such as the generalized bell function:

$$
{ }_{A}(x)=\frac{1}{1+\left[\frac{x-c_{i}}{a_{i}}\right]^{2 b_{i}}}
$$

Parameters in this layer are referred to as premise parameters.

Layer 2. Each node in layer 2 is labeled by $\Pi$ which multiplies the incoming data and sends the product out. For instance,

$$
\mathrm{O}_{i}^{2}=w i=\mu \operatorname{Ai}(\mathrm{x}) \times \mu \mathrm{B}(\mathrm{y}), \mathrm{i}=1,2 .
$$

Each node output represents the firing strength of a rule. Other T-norm operators which shows generalized AND can be used in layer 2.

Layer 3. Every node in this layer is a circle node labeled N. The i-th node calculates the ratio of the $i$-th rule's firing strength to the sum of all rules firing strengths:

$O_{i}^{3}=\bar{w}=\frac{w_{i}}{w_{1}+w_{2}}, \quad \mathrm{i}=1,2$.

The outputs of layer 3 will be mentioned as normalized firing strengths.

Layer 4. Every node i in this layer is a square node with a node function: 
International Journal of Computer Science \& Information Technology (IJCSIT) Vol 5, No 1, February 2013

$O_{i}^{4}=\bar{w}_{i} f_{i}=\bar{w}_{i}\left(p_{i} x+q_{i} y+r_{i}\right)$

$\bar{w}_{i}$ is the layer 3 output, while $\left\{\mathrm{p}_{\mathrm{i}}, \mathrm{q}_{\mathrm{i}}, \mathrm{r}_{\mathrm{i}}\right\}$ is the set of parameter. All parameter in this layer will be mentioned as consequent parameters.

Layer 5. The single node in this layer is a circle node labeled $\Sigma$ that computes the overall output as the summation of all incoming signals, i.e.,

$O_{i}^{5}=\sum \bar{w}_{i} f_{i}$

\subsection{Unsynchronized Sampling}

The procedure of short circuit fault location estimation in this study is use two terminals of electrical power transmission line as shown in Figure 3 [11].

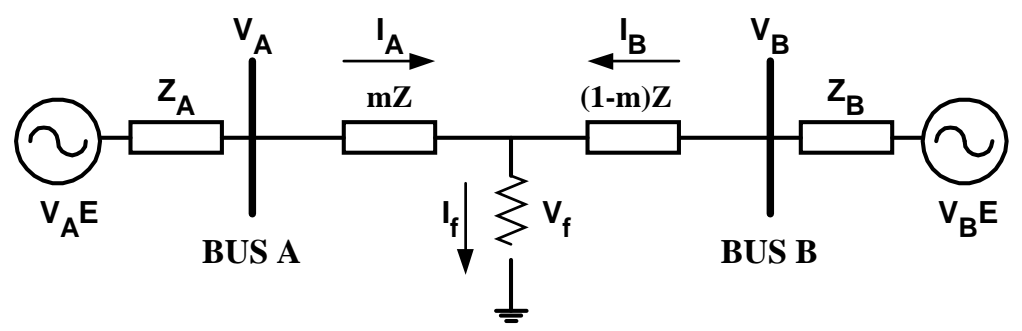

Figure 3. Short circuit fault in transmission lines.

Transmission line as shown in Figure 3, both voltage and current phasors from protected two terminals of the line are required in this procedure, but unsynchronized. As can be seen in Figure 3 , the method will estimate fault distance ' $\mathrm{m}$ ' from two ends of overhead electrical power transmission line.

The fault voltages and currents from bus A and bus B of transmission line are not synchronized, while $\delta$ is angle synchronization. For example, the voltage at bus A and bus B can be written as follow:

$V_{A}=\left|V_{A}\right| \angle \alpha_{m}+\delta ; \quad V_{B}=\left|V_{B}\right| \angle \beta_{m}$

where $\alpha_{\mathrm{m}}$ and $\beta_{\mathrm{m}}$ are measured angle from two ends respectively, and $\delta$ is the synchronization phasor angle between bus A and bus B. The similar equation can be written for current phasors. Hence, equation (10) has become:

$V_{A} e^{j \delta}-V_{B}+Z I_{B}=m Z\left(I_{A} e^{j \delta}+I_{B}\right)$

The unknown components of equation (11) are distance fault $\mathrm{m}$ and complex number $\delta=\mathrm{e}^{\mathrm{j} \delta}$. Equation (11) can be separated into real part and imaginary part to forms the new two equations as follow:

$\operatorname{Re}\left(V_{A}\right) \sin \delta+\operatorname{Im}\left(V_{A}\right) \cos \delta-\operatorname{Im}\left(V_{B}\right)+K_{4}=m\left(K_{1} \sin \delta+K_{2} \cos \delta+K_{4}\right)$

$\operatorname{Re}\left(V_{A}\right) \cos \delta-\operatorname{Im}\left(V_{A}\right) \sin \delta-\operatorname{Re}\left(V_{B}\right)+K_{3}=m\left(K_{1} \cos \delta-K_{2} \sin \delta+K_{3}\right)$ 
International Journal of Computer Science \& Information Technology (IJCSIT) Vol 5, No 1, February 2013

Coefficients of $K_{1}, K_{2}, K_{3}$, and $K_{4}$ in equation (12) and equation (13) can be defined as follow:

$K_{l}=R \operatorname{Re}\left(I_{A}\right)-X \operatorname{Im}\left(I_{A}\right)$

$K_{2}=R \operatorname{Im}\left(I_{A}\right)+X \operatorname{Re}\left(I_{A}\right)$

$K_{3}=R \operatorname{Re}\left(I_{B}\right)-X \operatorname{Im}\left(I_{B}\right)$

$K_{4}=R \operatorname{Im}\left(I_{B}\right)+X \operatorname{Re}\left(I_{B}\right)$

Then, the equation with unknown angle $\delta$ is formed. As rearranged the equations above, then the new equations are resulted as follow:

$a \sin \delta+b \cos \delta+c=0$

where,

$a=-K_{3} \operatorname{Re}\left(V_{A}\right)-K_{4} \operatorname{Im}\left(V_{A}\right)-K_{l} \operatorname{Re}\left(V_{B}\right)-K_{2} \operatorname{Im}\left(V_{B}\right)+K_{l} K_{3}+K_{2} K_{4}$

$b=K_{4} \operatorname{Re}\left(V_{A}\right)-K_{3} \operatorname{Im}\left(V_{A}\right)-K_{2} \operatorname{Re}\left(V_{B}\right)+K_{1} \operatorname{Im}\left(V_{B}\right)+K_{2} K_{3}-K_{1} K_{4}$

$c=K_{2} \operatorname{Re}\left(V_{A}\right)-K_{l} \operatorname{Im}\left(V_{A}\right)-K_{4} \operatorname{Re}\left(V_{B}\right)+K_{3} \operatorname{Im}\left(V_{B}\right)$

From the equation (18) can be seen that angle $\delta$ (synchronization angle) is unknown. The unknown one can be found by using Newton-Raphson iterative algorithm. The equation for iteratively to count the angle $\delta$ (in radian) is:

$\delta_{k+1}=\delta_{k}-\frac{F\left(\delta_{k}\right)}{F^{\prime}\left(\delta_{k}\right)}$

Iterative process will be stopped when the difference between two end values that smaller than the stated float is achieved, for example: $\delta_{k+1}-\delta_{k}<10^{-4}$. The procedure has the quadrate convergence and needs initial value for running the process. If voltage angle of two terminals of transmission line are zero respectively, then angle $\delta$ be apparent angle between two voltages and independent to synchronization error. As the synchronization has known, fault distance from one of two ends of line can be calculated from equation (12) and equation (13). From equation (12):

$m=\frac{\operatorname{Re}\left(V_{A}\right) \sin \delta+\operatorname{Im}\left(V_{A}\right) \cos \delta-\operatorname{Im}\left(V_{B}\right)+K_{4}}{K_{1} \sin \delta+K_{2} \cos \delta+K_{4}}$

If we use the equation (13), then fault distance $m$ from a transmission line terminal can be calculated as follow:

$m=\frac{\operatorname{Re}\left(V_{A}\right) \cos \delta-\operatorname{Im}\left(V_{A}\right) \sin \delta-\operatorname{Re}\left(V_{B}\right)+K_{3}}{K_{1} \cos \delta-K_{2} \sin \delta+K_{3}}$

Equation (23) and (24) can be used to all types of short circuit faults. This method can apply on overhead power transmission line with multi-phase cases. The amount of appropriate phase can be used in this method. 
International Journal of Computer Science \& Information Technology (IJCSIT) Vol 5, No 1, February 2013

And, error estimation can be calculated by the equation below [19]:

$$
\text { Errorestimation } \%)=\frac{\mid \text { actual location-estimated location }}{\text { line length }} \times 100 \%
$$

\section{Simulation RESUltS}

The procedure of this research is shown in Figure 4. Simulation of short circuit fault of transmission line has done by using EDSA software. Short circuit currents and voltages from both ends of overhead transmission line have used to input data of neuro-fuzzy method in Matlab environment. It is used as the main engineering tool for performing modelling and simulation of electric power systems, as well as for interfacing the user and appropriate simulation programs. MATLAB has been chosen due to availability of the powerful set of programming tools, signal processing, numerical functions, and convenient user-friendly interface. In this specially developed simulation environment, the evaluation procedures can be easily performed. We have used Fuzzy logic Toolbox of MATLAB to develop the ANFIS model with 2 inputs and single output as given in Figure 2. The simulations were performed by an Intel Pentium ${ }^{\circledR} \operatorname{core}(\mathrm{TM}) 2$ duo CPU, $1.80 \mathrm{GHz}, 4$ GB RAM.

For evaluating the performance of the proposed algorithm, the author adopts EDSA software for fault data generation and Matlab for neuro-fuzzy algorithm implementation. Power system shown in Figure 3 has selected for the studies reported in this paper. Bus A and bus B were considered to be connected by $150 \mathrm{kms}, 500 \mathrm{kV}$ transmission lines [21]. Two equivalent power systems considered to be connected to bus A and bus B. Electrical parameters of transmission lines and equivalent power sources are given in Table I.

TABLE I

ELECTRICAL PARAMETERS OF TRANSMISSION LINE IN THE STUDY

\begin{tabular}{l|c|c|c}
\hline \multirow{2}{*}{ Components } & \multicolumn{3}{|c}{ Impedances } \\
\cline { 2 - 4 } & $\begin{array}{c}\text { Positive sequence } \\
\left(\mathrm{Z}_{1}\right)\end{array}$ & $\begin{array}{c}\text { Negative sequence } \\
\left(\mathrm{Z}_{2}\right)\end{array}$ & $\begin{array}{c}\text { Zero sequence } \\
\left(\mathrm{Z}_{0}\right)\end{array}$ \\
\hline Transmission lines & $53,090 \angle 86,07^{\circ}$ & $53,090 \angle 86,07^{\circ}$ & $173,683 \angle 72,96^{\circ}$ \\
\hline Power source A & $4,001 \angle 89,03^{\circ}$ & $3,501 \angle 88,90^{\circ}$ & $1,414 \angle 45^{\circ}$ \\
\hline Power source B & $100,020 \angle 88,85^{\circ}$ & $75,027 \angle 88,47^{\circ}$ & $25,072 \angle 85,65^{\circ}$ \\
\hline
\end{tabular}


International Journal of Computer Science \& Information Technology (IJCSIT) Vol 5, No 1, February 2013

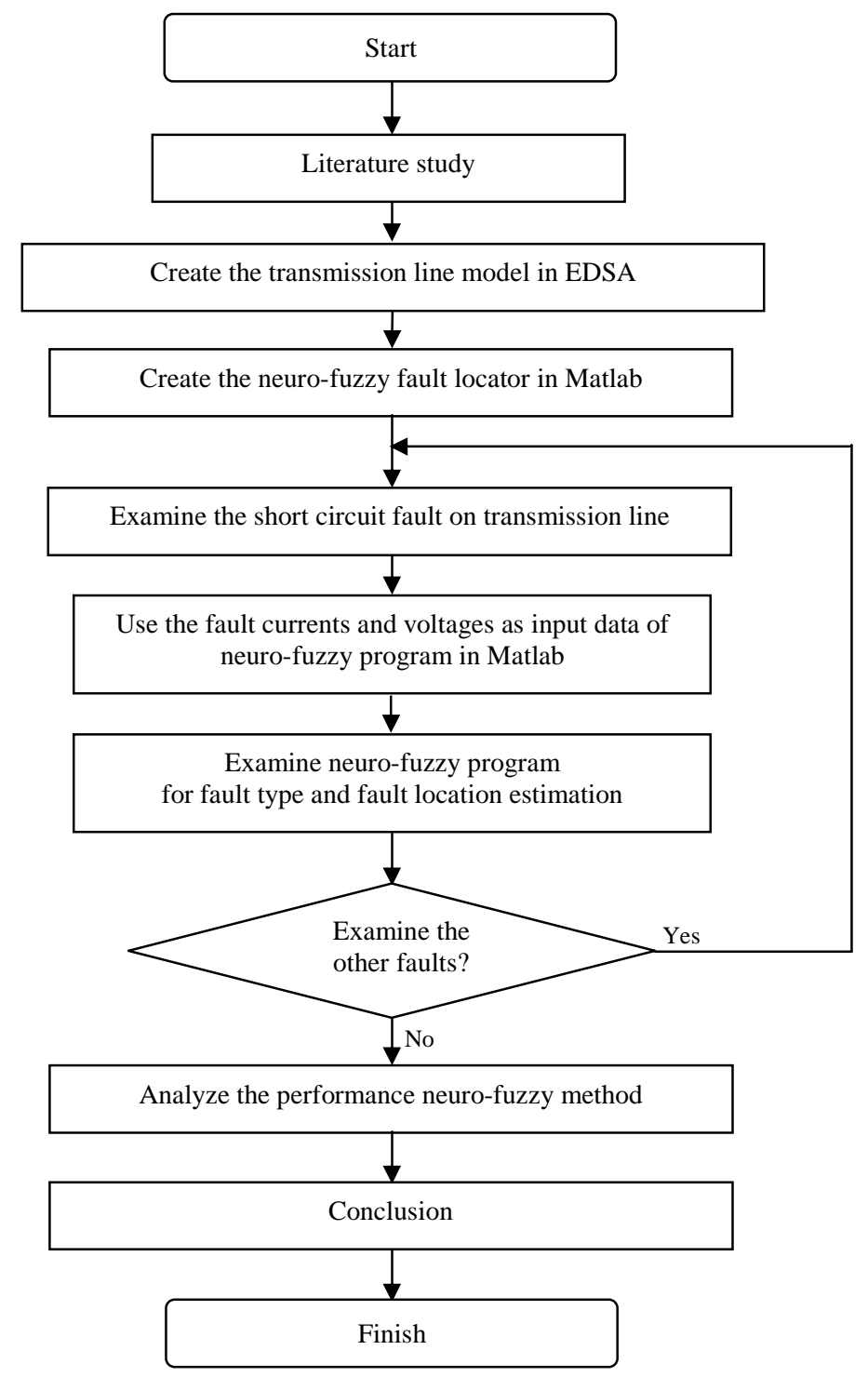

Figure 4. Procedure of the research.

In order to estimate the fault location of transmission line accurately, the fuzzy systems are trained with a separate ANFIS structure and suitable off-line data. The main steps of the procedure are (see Fig. 4):

Step 1: Create the architecture of fuzzy inference system (FIS) in Matlab environment. The architecture consist of two inputs (i.e. voltages and currents fault measured in the locator end of transmission line) and one output.

Step 2: Determine the membership functions for ANFIS input and output, recpectively, and then define the If-Then rules. In this work, gbell membership function has been choosen for each input and output of FIS architecture.

Step 3: Collecting or producing suitable information (data) to train ANFIS. The data for training process should have same form and the various conditions of a real power systemis included. A power system simulation using EDSA has been carried for achieving the suitable data. 
Step 4: Training process. The suitable data which are collected in step (3) are presented to network and adaptive nodes are adjusted. This presses will be stopped when error meet proposed goal. The nodes of adaptive properties update after entire patterns have been presented to network.

Step 5: Testing process. In training procedure, the fault locator should be given an acceptable output for unseen data. If test pattern output reached an acceptable range, fuzzy rule is adjusted in the best conditions.

Figure 5 shows the membership function of input variable "Voltage", while Figure 6 shows the membership function of input variable "Current". The voltage and current input variables have addressed as the the fault variables of transmission line under consideration. Figure 7 shows the training data of ANFIS and the ANFIS output for 20 epochs.

For pre-fault calculations, all transmission lines were modelled by equivalent pi networks and all loads were considered to be constant power loads. For calculating fault currents and voltages on the inception of a fault, the selected line has modelled by two equivalent pi networks, one for the section from bus A to the fault and the other for the section from bus B to the fault. For examining the fault distance technique, it was assumed that digital distance relays have been provided at the line terminals on bus A and bus B. It was also assumed that these digital distance relays measure fundamental frequency voltages and currents from sampled data.

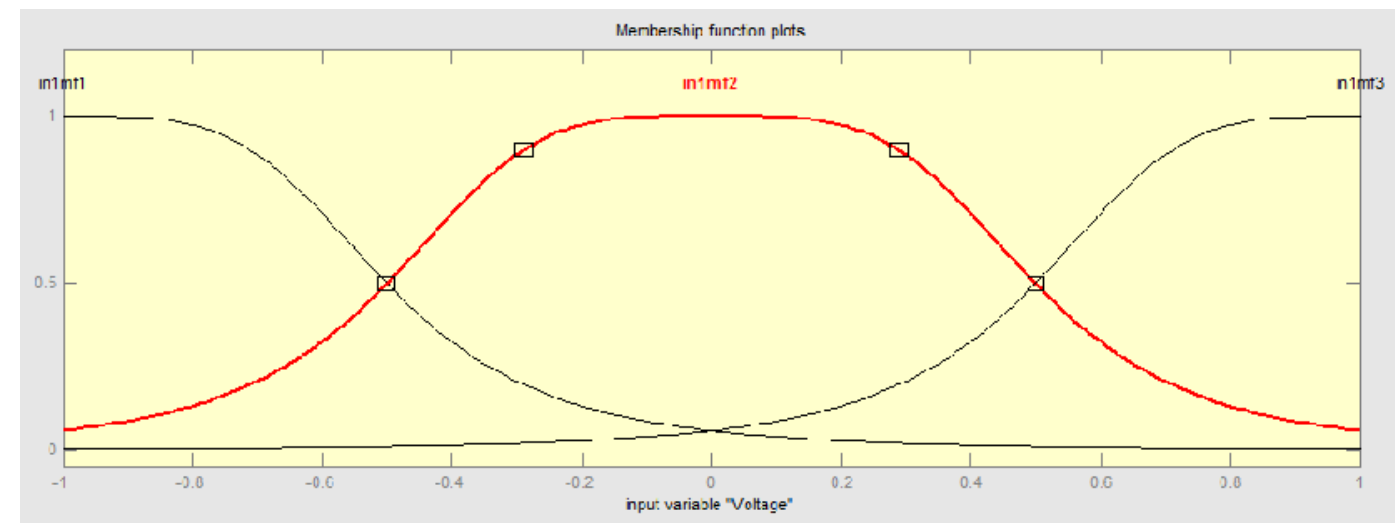

Figure 5. Membership function of input variable "Voltage".

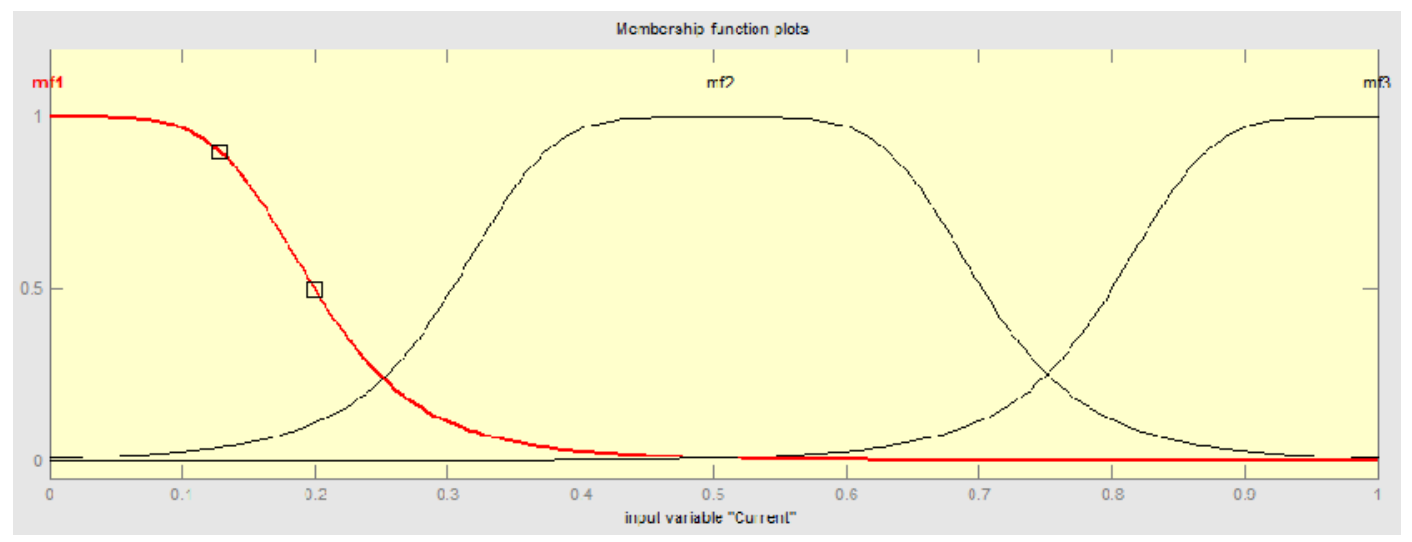

Figure 6. Membership function of input variable "Current". 
International Journal of Computer Science \& Information Technology (IJCSIT) Vol 5, No 1, February 2013

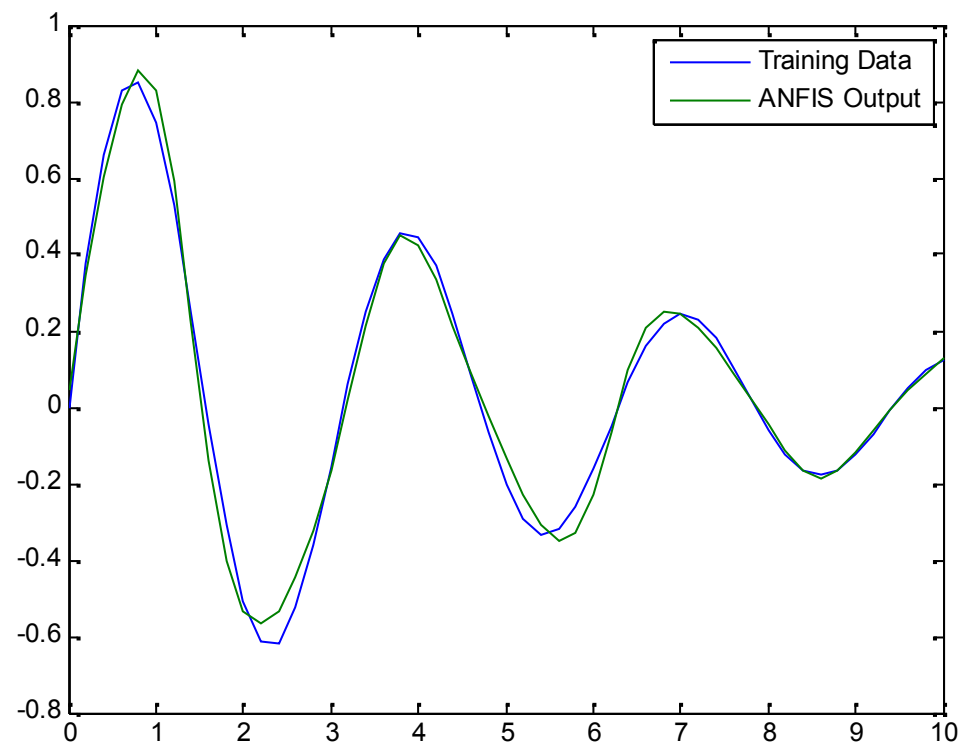

Figure 7. Training data of ANFIS and the ANFIS output.

TABLE II

FAult Distance Estimation FOR Single Phase-TO-GRound FAUlT

\begin{tabular}{c|c|c|c|c}
\hline \multirow{2}{*}{$\begin{array}{c}\text { Actual Distance } \\
(\mathrm{km})\end{array}$} & \multicolumn{4}{|c}{ Estimation Error $(\%)$} \\
\cline { 2 - 5 } & $\mathrm{R}_{\mathrm{f}}=0 \Omega$ & $\mathrm{R}_{\mathrm{f}}=10 \Omega$ & $\mathrm{R}_{\mathrm{f}}=50 \Omega$ & $\mathrm{R}_{\mathrm{f}}=100 \Omega$ \\
\hline 0 & 0,0027183 & 0,0024771 & 0,0093352 & 0,0170958 \\
\hline 15 & 0,0125956 & 0,0033028 & 0,0119279 & 0,0219511 \\
\hline 30 & 0,0090500 & 0,0080960 & 0,0221115 & 0,0390903 \\
\hline 45 & 0,0195715 & 0,0163435 & 0,0358773 & 0,0600260 \\
\hline 60 & 0,0211366 & 0,0280220 & 0,0532048 & 0,0847273 \\
\hline 75 & 0,0227297 & 0,0431110 & 0,0740820 & 0,1131887 \\
\hline 90 & 0,0243211 & 0,0615933 & 0,0985028 & 0,1454183 \\
\hline 105 & 0,0258992 & 0,0834552 & 0,1264669 & 0,1814347 \\
\hline 120 & 0,0274970 & 0,1086872 & 0,1579806 & 0,2212671 \\
\hline 135 & 0,0291193 & 0,1372857 & 0,1930578 & 0,2649561 \\
\hline 150 & 0,0307341 & 0,1582224 & 0,2184332 & 0,2962510 \\
\hline
\end{tabular}

In order to test the powerful of neuro-fuzzy method in this research, simulation of a single phase to ground fault has done in EDSA environment. The fault has occured on the selected location of transmission line. Buses A and B and some locations, i.e. $15 \mathrm{kms}, 30 \mathrm{kms}, 45 \mathrm{kms}, 60 \mathrm{kms}, 75$ kms, $90 \mathrm{kms}, 105 \mathrm{kms}, 120 \mathrm{kms}$, and $135 \mathrm{kms}$, were chosen as fault locations. Fault resistances were varied from $0 \mathrm{ohms}, 10 \mathrm{ohms}, 50 \mathrm{ohms}$, to $100 \mathrm{ohms}$. Fundamental frequency voltages at bus $\mathrm{A}$ and bus $\mathrm{B}$ and line currents were calculated and provided to the fault location program in 
Matlab as inputs. Fault location of a transmission line studies for single phase to ground fault are reported in this paper, as shown in Table II and Figure 8.

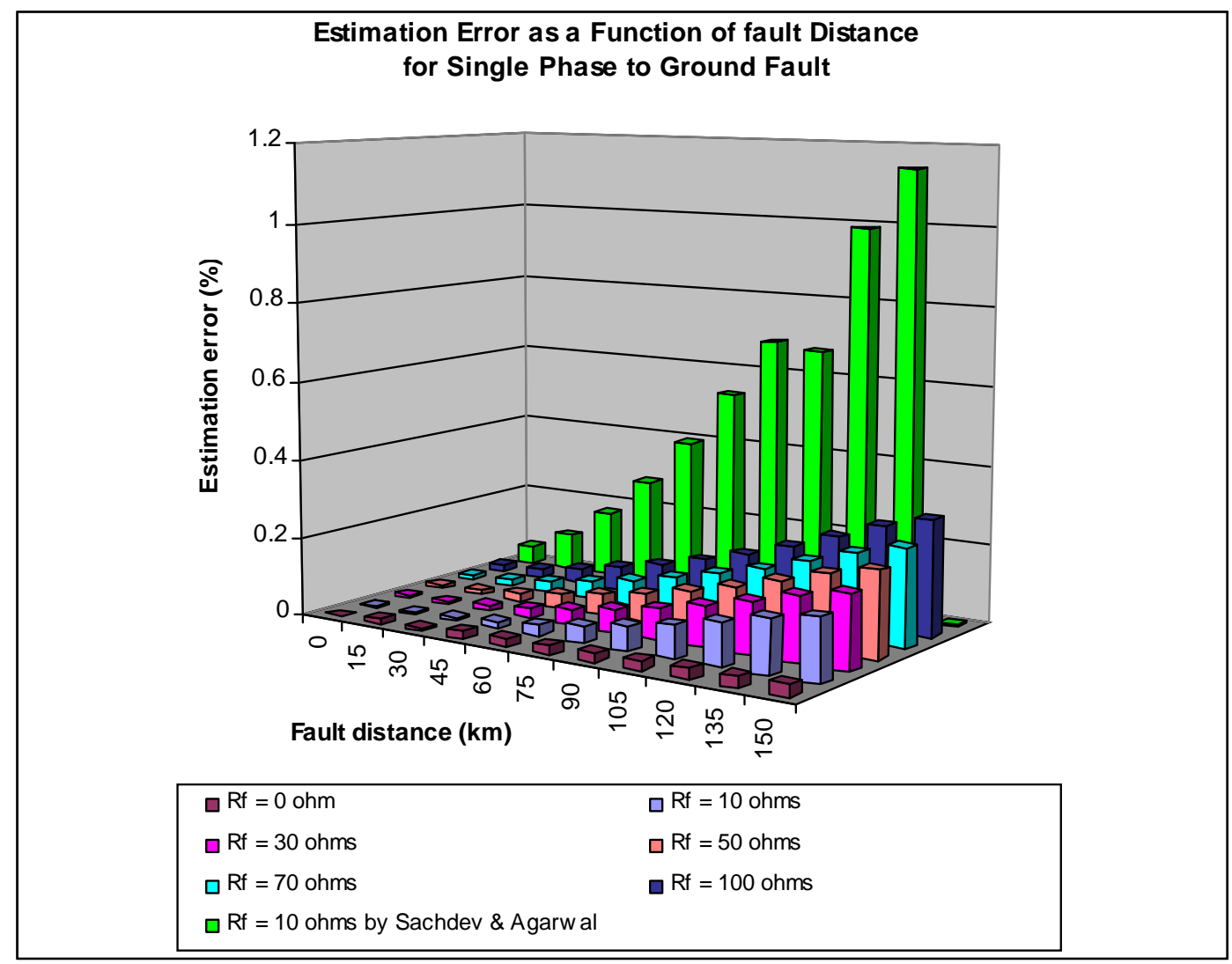

Figure 8. Estimation error as a function of fault distance for single phase to ground fault on transmission line.

Table II lists the estimation error of fault locations for a single phase to ground fault with fault resistances of $0 \mathrm{ohms}, 10 \mathrm{ohms}, 50 \mathrm{ohms}$, and $100 \mathrm{ohms}$, respectively. The estimation errors expressed as percentages of the line length are shown in Figure 5. The results indicate that distances of faults estimated by the proposed method are substantially more accurate than the distances estimated by Sachdev and Agarwal [22]. When a single phase to ground fault occurs in bus A ( $0 \mathrm{kms}$ distance) with fault resistance of $0 \mathrm{ohms}$, the estimation error is $0.0027 \%$. This error value is the smallest estimation error in the study. As can be seen in Table II and Figure 8 that the highest short circuit fault estimation error for single phase to ground fault is $0.2962 \%$ at distance of $150 \mathrm{kms}$ with fault resistance of $100 \mathrm{ohms}$.

\section{Conclusions}

This paper has proposed a neuro-fuzzy approach that estimates the distance of a transmission line short circuit fault from relay locations using unsynchronized fundamental frequency voltages and currents measured at the two ends of transmission line. In this paper, a neuro-fuzzy aprroach for short circuit fault location estimation which uses data from both ends of overhead transmission line is described. The approach utilizes the advantages of digital relaying which are available today. The accurate fault location estimation algorithm has irrespective of source impedances, fault resistances, fault types, and load currents. Simulation of short circuit fault of transmission 
line has done by using EDSA software. Short circuit currents and voltages from both ends of overhead transmission line have used to input data of neuro-fuzzy method in Matlab program. Simulation results demonstrate the accuracy of the method. The results shows that the lowest estimation error for single phase to ground fault with the variation of fault resistances of $0 \mathrm{ohms}$, $10 \mathrm{ohms}, 50 \mathrm{ohms}$, and $100 \mathrm{ohms}$, respectively, is $0.0027 \%$, while the highest estimation error is $0.2962 \%$.

\section{ACKNOWLEDGEMENTS}

The author would like to thank profusely and the highest appreciation for DIKTI (the Directorate General of Higher Education) Ministry of Education and Cultural Affairs, Republic of Indonesia, for having funded this research.

\section{REFERENCES}

[1] Ram, B. and Vishwakarma, DN, "Power System Protection \& Switchgear", pp. 3-6, McGraw-Hill Pub. Co. Ltd., New Delhi, 1995.

[2] A.M. Borbely and J.F. Kreider, "Distributed Generation: The Power Paradigm for the New Millennium”, CRC Press, Washington D.C., 2001.

[3] T. Takagi, Y. Yamakoshi, M. Yamuaura, R. Kondow, and T. Matsushima, "Development of a New Type of Fault Locator Using One Terminal Voltage and Current Data", IEEE Trans. On Power Apparatus and System, vol. PAS-101, No 8, pp. 2892-2898, Aug. 1982.

[4] Eriksson, L., S.D. Rockfeller and M. Saha, "Accurate Fault Loc. with Compensation for Apparent Reac. in the Fault Resistance Resulting from Remote End in Feed", IEEE Transactions on Power Aparatur and System, PAS-104, No 2, 1985.

[5] D. Novosel, D.G. Hart, M.M. Saha, and S. Gress, "Optimal fault location for transmission system", ABB Review 8, pp. 20-27, 1994.

[6] A. Sauhats and M. Danilova, "Fault Location Algorithms for Super High Voltage Power Transmission Lines", in Proc. Of IEEE Bologna Power Tech Conf., 2003.

[7] A. Sauhats and M. Bockarjova, "Algorithms, Means and Tools of Fault Location on Transmission Lines”, Proc. EPE-PEMC'2004, Riga, Latvia, 2004.

[8] Lian, B and M.M.A. Salama, "An Overview of Digital Fault Location Alg. For Transmission Line Using Transient Waveforms”, Electric Power System Research, Vol. 29, No. 1, pp. 17-25, 1994.

[9] L.B. Sheng and S. Elangovan, "A fault location algorithm for transmission lines", Electric Machines \& Power Syst., Vol. 26, No. 10, pp. 991-1005, 1998.

[10] Q. Zhang, Y. Zhang, W. Song, and Y. Yu, "Transmission line fault location for phase-to-earth fault using oneterminal data", IEE Proc. Trans. Distribution., Vol. 146, No. 2, pp. 121-124, 1999.

[11] Kezunovic, M and J. Mrkic, “An Accurate Fault Location Alg. Using Sync. Sampling”, Electric Power System Research, Vol. 29, No. 3, pp. 161-169, 1994.

[12] Novosel, D., E. Udren, J. Garitty and D.G. Hart, "Unsynchronized Two Terminal Fault Location Estimation", IEEE Transactions on Power Delivery, Vol. 11, No. 1, pp. 130-138, 1996.

[13] Aggarwal, R.K., A.T. Johns, D.V. Coury and A. Kalam, "A Practical Approach to Accurate Fault Location on EHV Teed Feeders", IEEE Transactions on Power Delivery, Vol. 8, pp. 874-883, July 1993.

[14] A.A. Girgis, D.G. Hart, and W.L. Peterson, "A new fault location technique for two-and threeterminal lines", IEEE Trans. Power Delivery, Vol. 7, No.1, pp. 98-107, January 1992.

[15] Tziouvaras, D.A., G. Benmmouyal and J. Roberts, "New multi-ended fault location design for two- or three-terminal lines", Proc. 7th Int. IEE Conf. on Dev. in Power System Protection, pp. 395-398, April 2001.

[16] Lin, Y., C. Yu and C. Liu, "A New Fault Locator for Three Terminal Transm. Lines Using Two Terminal Sync. Volt. And Cur. Phasors", IEEE Transactions on Power Delivery, Vol. 7, No.3, pp. 452-459, July 2002.

[17] R. Syahputra, "Fuzzy Multiple Objective App. for the Improvement of Distribution Net. Efficiency by Considering Distributed Generation”, IJCSIT, Vol 4, No 2, April 2012. 
International Journal of Computer Science \& Information Technology (IJCSIT) Vol 5, No 1, February 2013

[18] Brahma, S.M., "Fault Location Scheme for a Multi Terminal Transm. Line Using Synch. Voltage Measurements", IEEE Transactions on Power Delivery, Vol. 20, No. 2, pp. 1325-1331, April 2005.

[19] Jang, J.S.R., 1993, "ANFIS: Adaptive-Network-based Fuzzy Inference System", IEEE Trans. Syst., Man, Cybern., 23, 665-685, June.

[20] B. R. Oswald and A. Panosyan, "A New Method for the Computation of Faults on Transmission Lines”, IEEE PES Transmission and Distribution Conference and Exposition Latin America, Venezuela, 2006.

[21] Izykowski, J., M.M. Saha, E. Rosolowski, P. Balcerek and M. Fulczyk, "A Fault Location Method for the Application with Current Dif. Relays of Three Terminal Lines", IEEE Transactions on Power Delivery, Vol. 22, No. 4, pp. 2099-2107, October 2007.

[22] M.S. Sachdev and R. Agarwal., "A Technique for Estimating Overhead Transmission Line Fault Locations from Digital Impedance Relay Measurements", IEEE Transactions on Power Delivary, Vol. 3, No. 1, pp. 121-129, 1988.

\section{AUTHOR}

Ramadoni Syahputra received B.Sc. degree in Electrical Engineering from Institut Teknologi Medan and M.Eng. degree from the Electrical Engineering Department, Engineering Faculty, Gadjah Mada University, Yogyakarta, Indonesia, in 1998 and 2002, respectively. He was with the Electrical Engineering Department, Engineering Faculty, Universitas Muhammadiyah Yogyakarta (UMY), Indonesia. His research interests include computational of power system, artificial intelligence in power system, power system operation, power system control, power quality, distributed generation, and renewable energy.

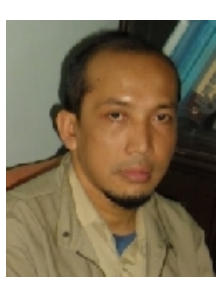

